\title{
Large-Scale Direct Shear Test on Tire Slice Reinforced Crushed Concrete Particles
}

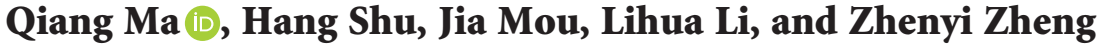 \\ Hubei University of Technology, School of Civil Engineering and Architecture, Wuhan 430068, China \\ Correspondence should be addressed to Qiang Ma; maqiang927@163.com
}

Received 20 June 2019; Revised 13 February 2020; Accepted 21 February 2020; Published 13 March 2020

Academic Editor: Antonio Gloria

Copyright (C) 2020 Qiang Ma et al. This is an open access article distributed under the Creative Commons Attribution License, which permits unrestricted use, distribution, and reproduction in any medium, provided the original work is properly cited.

In order to study the mechanical properties of tire slices reinforced crushed concrete particles, a series of shear tests were carried out under the conditions of different vertical loads, different tire volume contents, and different shear rates. The test results show that the addition of tire slices can increase the internal friction angle and cohesion of concrete particles, therefore increase the shear strength of crushed concrete particles. The peak shear stress increases with the increase of vertical load. However, with the increase of the tire volume content, the reinforcement effect of the tire slices first increases and then decreases, and the effect is best when the tire volume content is $4 \%$. Under the vertical load of $60 \mathrm{kPa}$, the reinforcement effect of $4 \%$ tire volume content is the best, and the peak shear stress increases by $46.53 \%$. Additionally, the shear rate has a little effect on the peak shear stress. The larger the shear rate is, the smaller the shear displacement is and the faster the shear strength decreases. The smaller the shear rate is, the more gently the shear strength decreases.

\section{Introduction}

With the rapid increase in the number of automobiles, how to deal with a large number of waste tires and further meet the needs of energy conservation and environmental protection have become an unavoidable problem; waste tires were in urgent need of treatment. The reuse of waste tires can be divided into several ways, such as retreading old tires, producing rubber powder from waste tires, and making recycled rubber [1-3]. However, in any form, the utilization rate of used tires was relatively low, and the overall utilization rate was only about $45 \%$. Nowadays, many scholars have confirmed the feasibility of waste tires as reinforcing materials [4-7]. In order to better understand the behavior of rubber-soil mixtures, scholars conducted a series of laboratory experiments to study their characteristics. Siddique and Naik [8] used waste tire rubber to prepare rubber concrete mixture and introduced the possible use of rubber concrete, which provided a basis for the combination of waste tire and construction waste to fill. In order to further explore the feasibility of tire reinforcement, a series of laboratory tests were carried out, and the results confirmed that the waste tire can be used as the reinforcement material of soil and can be effectively applied to geotechnical engineering [9-11]. Ghazavi and Sakhi [12] mixed tire slices of different sizes and contents into sandy soil and investigated the shear strength and the deformation properties of the mixed soil through large-scale direct shear tests. Similar direct shear tests obtained the same conclusion that the tire reinforced composite soil could improve its shear strength and reduce the deformation [13-15]. After a lot of tests, it is found that the mechanical properties of the tire were not the same when it is mixed with different materials. When the sand particles and the tire slices are mixed in a certain proportion, the bearing capacity of the soil particle rubber mixture increases and the bearing capacity decreases with the increase of the tire particles to a certain extent [16]. However, when the soil particles are mixed with the tire debris, the shear modulus and damping ratio decrease with the increase of the tire debris content and the shear modulus increases with the increase of the confining pressure [17]. In addition, a series of triaxial tests on sand mixed with different proportion of shredded tires were conducted [18-20], and shear strength of the sand-tire mixtures had been found 
to decrease with the increment in the amount of tire crumbs in the mixtures.

At the same time, with the rapid development of society and economy, the construction waste formed in China is increasing day by day. Construction waste accounts for about $30 \% \sim 40 \%$ of the total urban waste, but the utilization rate is only $5 \%$. Most of the construction waste has caused serious environmental pollution and resource waste without any treatment [21]. Many scholars verified the feasibility of construction waste as pavement base filling, providing guidance for the determination of the existence of construction waste [22-24]. Rao et al. [25] introduced the engineering performance of construction waste as recycled aggregate and summarized the influence of the use of recycled aggregate on the performance of concrete. Vieira et al. [26] studied the use of fine construction waste as the filling material of the reinforced structure and evaluated the physical, mechanical, and environmental characteristics of construction waste filling. Tang et al. [27] studied the mechanical properties and permeability of waste tire concrete (waste tire as the concrete aggregate). The results showed that the elastic modulus, compressive strength, and tensile strength of waste tire concrete were generally lower than those of ordinary concrete, and the difference was significant with the increase of the content waste tire percentage.

Above all, this paper focuses on the shear mechanical properties of tire slices reinforced crushed concrete particles. The optimum volume content of tire slices and the interaction mechanism between tire slices and concrete particles are discussed. Therefore, a series of shear tests have been carried out on the reinforced concrete with different volume contents, different vertical loads, and different shear rates. The results can present an important reference for the application of unconventional material waste tire reinforced concrete particles.

\section{Test Preparation}

2.1. Test Equipment. The equipment used in the test is ShearTrac III laboratory large-scale direct shear apparatus produced by Geocomp Company, USA, as shown in Figure 1. The internal dimension of the upper shear box is $305 \mathrm{~mm} \times 305 \mathrm{~mm} \times 100 \mathrm{~mm}$ (length $\times$ width $\times$ height), and the internal dimension of the lower shear box is $405 \mathrm{~mm} \times 305 \mathrm{~mm} \times 100 \mathrm{~mm}$ (length $\times$ width $\times$ height $)$ The length of the lower shear box in the shear direction is longer than that of the upper shear box in order to remain the shear area during the shear process. The equipment can be used for direct shear test under controlled displacement and stress parameters. In this test, the controlled displacement parameters are used for the direct shear test. The movement of the shear box in horizontal direction is controlled by a series of gears driven by a high precision motor. The maximum shear displacement in horizontal direction is $100 \mathrm{~mm}$. The adjustable shear rate ranges from $0.00003 \mathrm{~mm} \cdot \mathrm{min}^{-1}$ to $15 \mathrm{~mm} \cdot \mathrm{min}^{-1}$. The horizontal and the vertical displacements are measured by LVDT sensors. Vertical loads are applied by hydraulic jacks which were supported by the reaction frames, and the forces are spread to the soil through rigid load plates above the soil. The test data are automatically recorded by the attached software.

2.2. Test Method. The materials used in this test were construction waste obtained from Wuhan area. First, the construction waste should be preliminarily selected, stacked by category, removed from large steel bars, and selected manually. After cleaning, the block and concrete block would be crushed into particles. Finally, manual screening was adopted, and the grading of concrete particle screening results is as shown in Figure 2. According to the classification method proposed in the Chinese specification of "Test Methods of Soils for Highway Engineering," the test soil sample was named coarse-grained soil with a water content of $5.6 \%$.

The waste tire slice was taken from the 145/70R12 standard car tire. The waste tires were cut into long strips with a length of $50 \mathrm{~mm}$ and a width of $30 \mathrm{~mm}$. The mechanical parameters of the tire slices are shown in Table 1.

Using the artificial uniform mixing and reinforcement, even the scrap tire slices were randomly distributed in the concrete particles. Tire slices with different volume contents were mixed with concrete particles. The moisture content of the sample of the tire slice reinforced concrete particles was controlled to be $5 \%$, and the sample was loaded after the moisture content stabilized. The mixture samples were filled within 5 layers, each of which had a thickness of $4 \mathrm{~cm}$, and a compaction of 25 times was conducted in each layer. The dry density of the sample was $1.77 \mathrm{~g} \cdot \mathrm{cm}^{-3}$, and the relative compactness was $60.3 \%$.

2.3. Test Scheme. In order to study shear behavior of the interface of reinforcement with different shear rates, a series of shear tests were carried out under different vertical loads, different shear rates, and different volume contents of tire slices in reinforcement. The parameters setting for the test scheme are listed in Table 2.

It is worth noting that there are effects of repeatability and deviation in the test. The main reason is that if the properties of a group of test samples are very different, it will lead to deviation between the test results and the theoretical values. Therefore, the test is repeated in each group, and the average value is taken as the test result so that the test result has credibility and representativeness.

\section{Test Results and Analysis}

\subsection{Influence of Vertical Load on Interface Characteristics of} Reinforcement. Figure 3 shows the shear stress-shear displacement curves of pure concrete particles under three loading levels. When the vertical load was $30 \mathrm{kPa}, 60 \mathrm{kPa}$, and $90 \mathrm{kPa}$, the corresponding peak shear strength of concrete particles was $48.4 \mathrm{kPa}, 98 \mathrm{kPa}$, and $141 \mathrm{kPa}$, respectively.

It can be seen from Figure 3 that the shear stress-shear displacement curves under the vertical load of $30 \mathrm{kPa}$, $60 \mathrm{kPa}$, and $90 \mathrm{kPa}$ showed obvious softening characteristics. This phenomenon was the same as the research carried out 


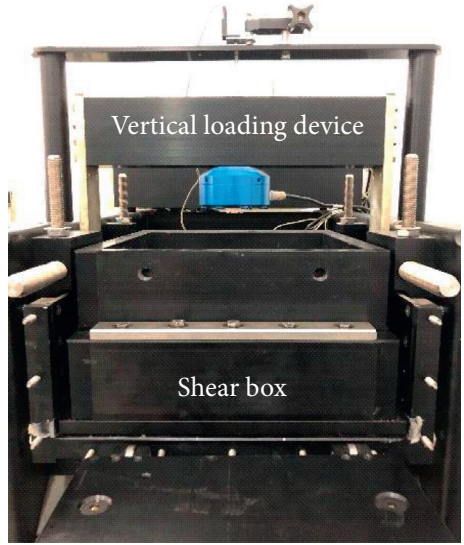

(a)

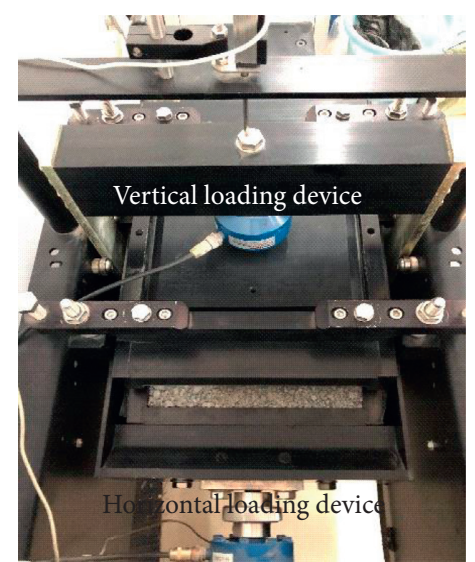

(b)

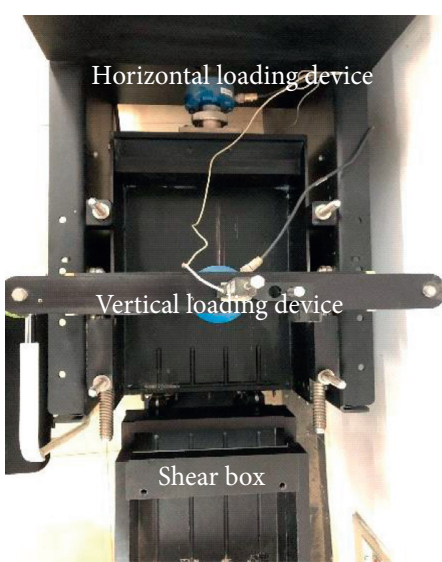

(c)

Figure 1: ShearTrac III large direct shear instrument. (a) Main view, (b) side view, and (c) top view.

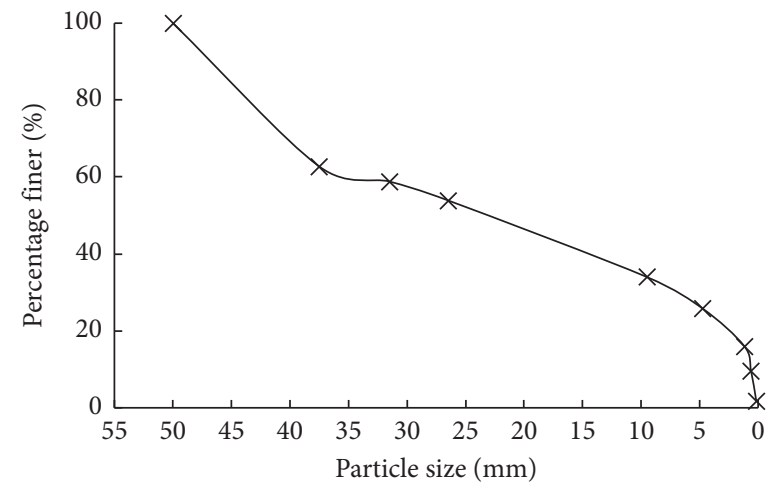

FIGURE 2: Grading curve of concrete.

TABLE 1: Mechanical parameters of waste tire slices.

\begin{tabular}{lccccc}
\hline Width $(\mathrm{mm})$ & Thickness $(\mathrm{mm})$ & Relative density & Tensile strength $(\mathrm{MPa})$ & Elastic modulus $(\mathrm{MPa})$ & Poisson's ratio \\
\hline 10 & 5 & 1.2 & 12 & 200 & 0.33 \\
\hline
\end{tabular}

TABLe 2: Shear test scheme.

\begin{tabular}{lccc}
\hline Working condition & Tire slice volume content $(\%)$ & Vertical load $(\mathrm{kPa})$ & \left.${\text { Shear rate }\left(\mathrm{mm}^{\mathrm{m}} \mathrm{min}\right.}^{-1}\right)$ \\
\hline A1 & 2 & & 1 \\
A2 & 4 & $30 / 60 / 90$ & \\
A3 & 6 & & 0.5 \\
A4 & 0 & 60 & 2 \\
B1 & 2 & & 5 \\
B2 & & & \\
B3 & & & \\
\hline
\end{tabular}

by Infante et al. [28]. As the shear displacement increased, the shear stress increased first and then decreased and then decreased after reaching the peak value. Shear stress and its peak increased with the increase of vertical load. These results were similar with that reported by Vieira and Pereira [29]. In addition, when the shear displacement was small, the slope of the shear stress-shear displacement curve under different vertical loads was close; however, as the shear displacement increased gradually, sample under different vertical loads of shear stress and shear displacement relationship curve slope gradually opened and the gap was increasing. The results show that when the shear displacement was large, the vertical load had a more significant effect on the shear stress.

The larger the vertical load, the larger the shear displacement which reached the peak shear strength. When the 


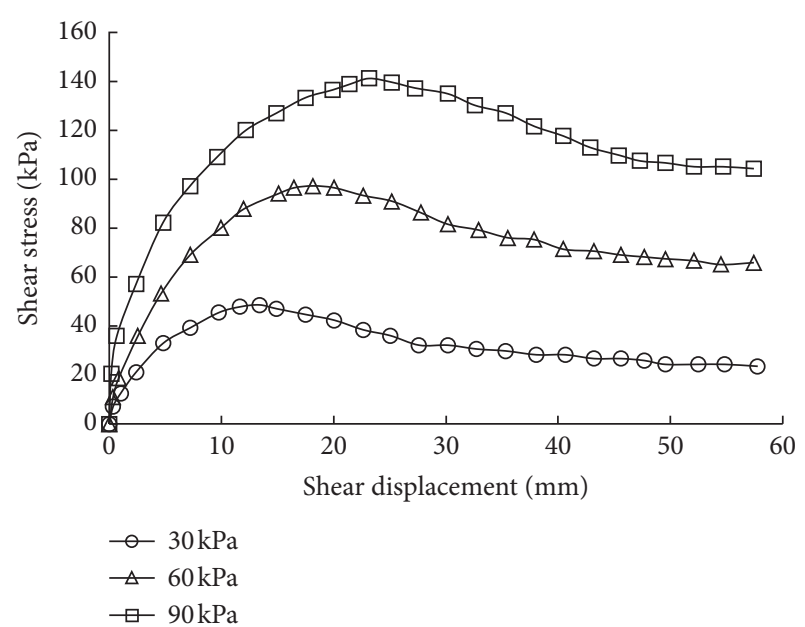

FIGURE 3: Shear stress-shear displacement curves of concrete particles.

vertical load is low $(30 \mathrm{kPa})$, the shear strength reaches its maximum value when the shear displacement is about $10 \mathrm{~mm}$; when the vertical load is medium $(60 \mathrm{kPa})$, the shear strength reaches its maximum value when the shear displacement is about $15 \mathrm{~mm}$; when the vertical load is large $(90 \mathrm{kPa})$, the shear strength reaches its maximum value when the shear displacement is about $20 \mathrm{~mm}$. The reason is that when the vertical load was small, the movement of concrete particles was relatively easy and the relative displacement could quickly reach a stable state. However, when the vertical load was large, the interaction between particles was large and the displacement was relatively difficult, so a larger shear displacement was needed to achieve a more stable state.

3.2. Influence of Tire Slice Percentage on the Shearing Behavior of Reinforcement. In order to investigate the effect of the tire volume content on the peak shear stress of the samples, shear tests with different tire volume contents were performed under the identical vertical load. The shear stress-shear displacement curves of tire slices reinforced concrete particles with different tire volume contents are shown in Figure 4.

From Figure 4, it can be seen that the peak shear stress increases with the increase of vertical load, when the vertical load was $30 \mathrm{kPa}, 60 \mathrm{kPa}$, and $90 \mathrm{kPa}$, respectively. The peak shear stresses of samples of $2 \%$ tire volume content were $64 \mathrm{kPa}, 135.6 \mathrm{kPa}$, and $182 \mathrm{kPa}$, respectively, those of $4 \%$ tire volume content were $66.5 \mathrm{kPa}, 143.6 \mathrm{kPa}$, and $187.3 \mathrm{kPa}$, respectively, and those of $6 \%$ tire volume content were $63.2 \mathrm{kPa}, 132.6 \mathrm{kPa}$, and $179.6 \mathrm{kPa}$, respectively. As the tire volume content increased, the peak shear stress increased first and then decreased because the optimal tire volume content was between $2 \%$ and $6 \%$ under the identical vertical load.

Figure 4(a) shows that compared with the pure concrete particles in Figure 3, the peak shear stress increased by $32.23 \%, 38.37 \%$, and $29.08 \%$, respectively. Figure 4 (b) shows that when the vertical load was $30 \mathrm{kPa}, 60 \mathrm{kPa}$, and $90 \mathrm{kPa}$, the peak shear stress increased by $37.4 \%, 46.53 \%$, and $32.84 \%$, respectively. Under different vertical loads, the peak shear stress of $4 \%$ tire volume content was higher than that of $2 \%$. Figure 4 (c) shows that, under the vertical loads of $30 \mathrm{kPa}, 60 \mathrm{kPa}$, and $90 \mathrm{kPa}$, the peak shear stress of $6 \%$ tire volume content increased by $30.58 \%, 35.31 \%$, and $27.38 \%$, respectively. Compared with Figures $4(\mathrm{a})-4(\mathrm{c})$, the effect of $2 \%$ tire volume content is better than that of $6 \%$, and $4 \%$ tire volume content has the best effect.

3.3. Effect of Shear Rate on Interface Characteristics of Reinforced Soil. Figure 5 shows the relationship between shear stress and shear displacement at different shear rates.

From Figure 5, it can be seen that the curves obtained under different shear rates were close within the range of shear rates studied in this experiment, indicating that the shear rate had little effect on the peak shear stress of the sample. After the shear displacement reached about $17 \mathrm{~mm}$, the interfacial shear rate decreased gradually. The faster the shear rate was, the smaller the shear displacement which reached the peak value of shear stress was. When the shear rate was $5 \mathrm{~mm} \cdot \mathrm{min}^{-1}$, the maximum shear stress reached its peak value, and the peak value was slightly higher than the rate of $0.5 \mathrm{~mm} \cdot \mathrm{min}^{-1}, 1 \mathrm{~mm} \cdot \mathrm{min}^{-1}$, and $2 \mathrm{~mm} \cdot \mathrm{min}^{-1}$. The higher the shear rate is, the greater the slope of the decline after the peak shear stress reached; the smaller the rate is, the smaller the slowdown speed after the peak shear stress reached and finally tended to be stable.

\subsection{The Influence on Cohesion and Internal Friction Angle.} Figures 6 and 7 are shear strength parameter of reinforced concrete particles with different tire volume contents.

From Figure 6, it can be seen that the cohesion of reinforced concrete particles increased first and then decreased with the increase of the reinforcement ratio. The curve reaches its peak when the tire volume content is $4 \%$. Compared with pure concrete particles, the cohesion of reinforced concrete particles increased greatly, and the cohesion increased by $8.5 \mathrm{kPa}$. From Figure 7, it can be seen that the angle of internal friction varies from $57.3 \sim 63.4^{\circ}$. Namely, the cohesion and internal friction angle of concrete particles with tire slices were higher than those of pure concrete particles. The results showed that the shear strength of reinforcement was affected by the tire volume content, and after reinforcement the crushed concrete particles had larger cohesion and internal friction angle.

3.5. The Optimum Tire Volume Content. Through the analysis of Figure 6, it can be seen that the effect of the tire volume content on the shear strength of the samples increased first and then decreased. When the tire volume content was $4 \%$, the reinforcing effect of tire slices on concrete particles was the most significant. The reason is that when the volume of the tire slice is less than $2 \%$, the effect between the tire slices and concrete particles is limited and the contribution to the friction and cohesion between reinforcement and soil is also small. The contribution of tire 

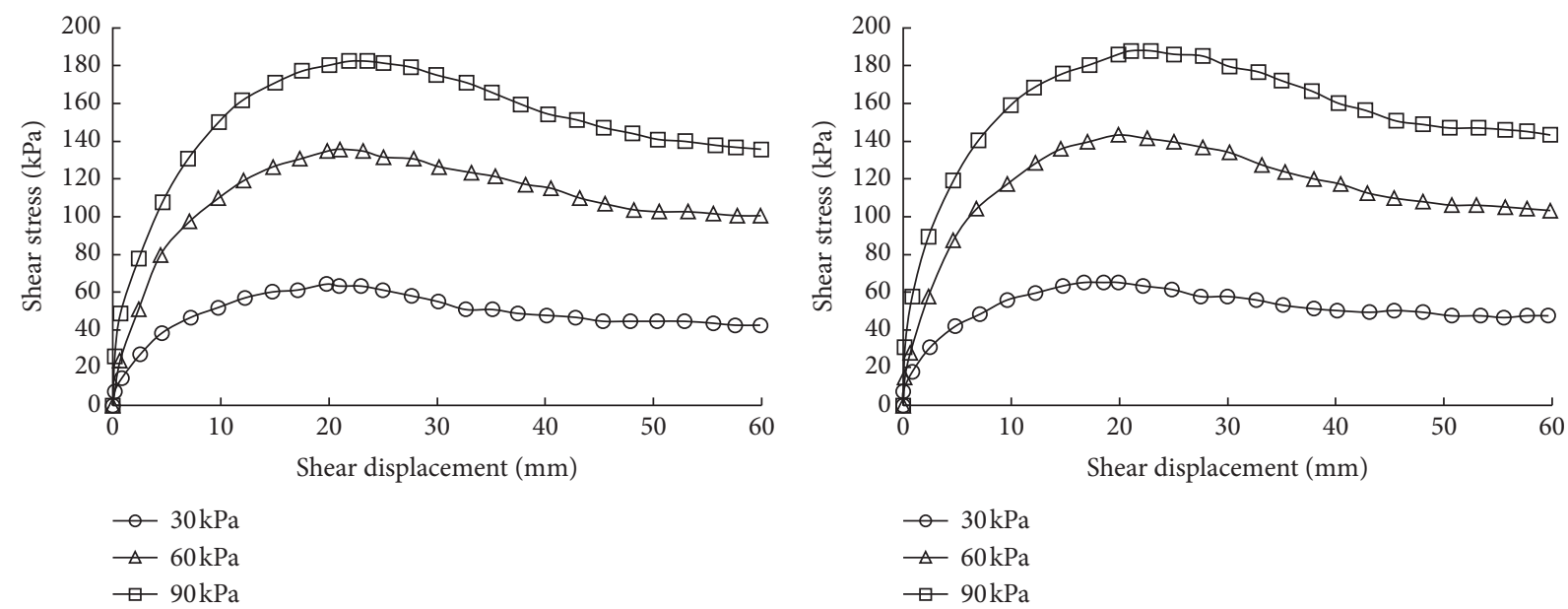

(a)

(b)

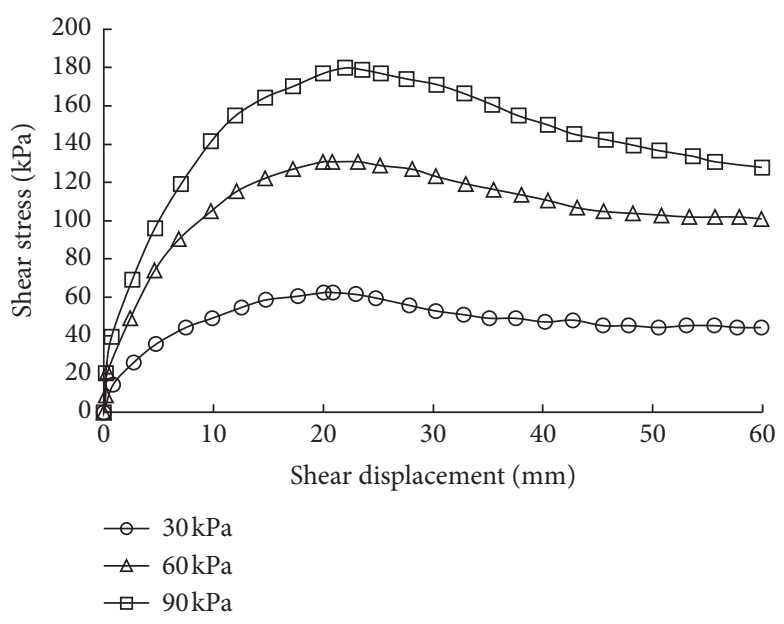

(c)

FIGURE 4: Shear stress-shear displacement curves of tire slices reinforced concrete particles with different tire volume contents. (a) $2 \%$ tire volume content, (b) $4 \%$ tire volume content, and (c) $6 \%$ tire volume content.

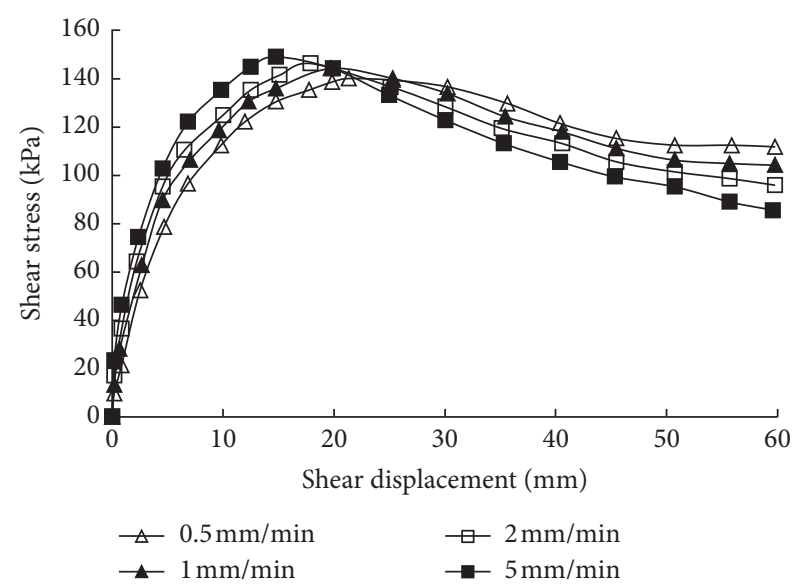

Figure 5: Shear stress-shear displacement relationship at different shear rates.

slices to the shear strength of the samples increased with the increase of the tire volume content. When the tire volume content reached $4 \%$, the reinforcement effect reached the

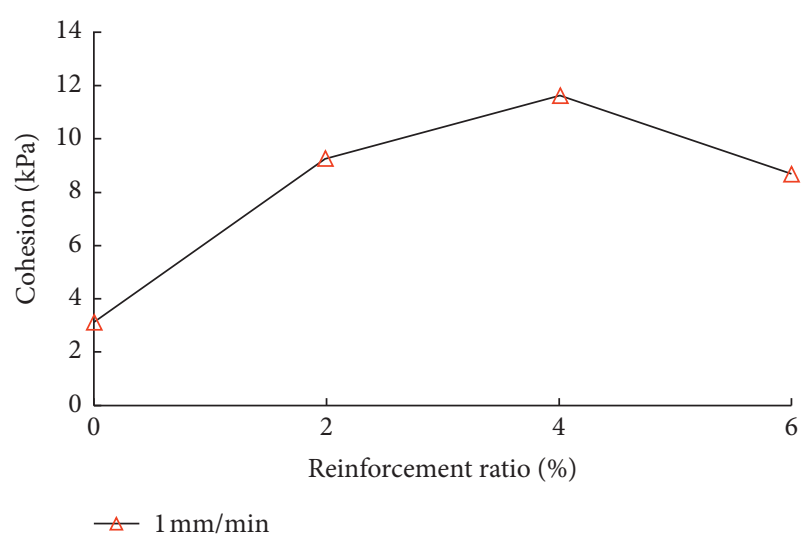

FIgURE 6: The relationship between reinforcement ratio and cohesion.

best state. The continuous increase in the tire volume content caused excessive accumulation of tires and overlaps, which prevented the tires from fully contacting the concrete particles. As a result, the cohesion and friction provided by 


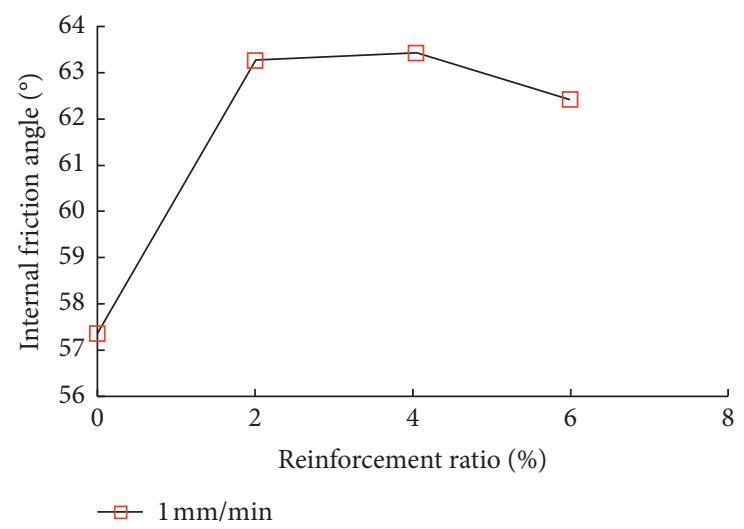

FIgURE 7: The relationship between reinforcement ratio and angle of internal friction.

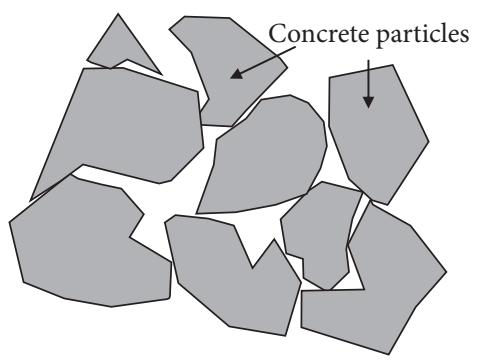

(a)

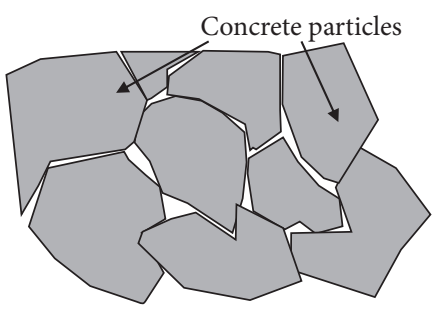

(b)

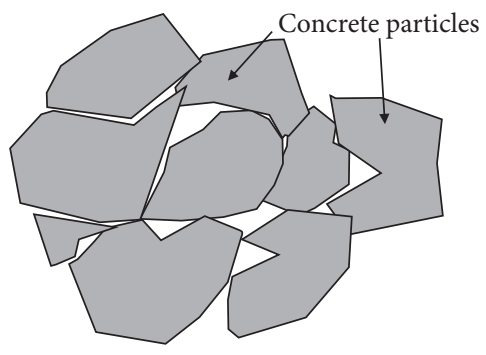

(c)

FIGURE 8: Changes of concrete particles under external loads. (a) Load-free state, (b) limit equilibrium state, and (c) balance broken state.

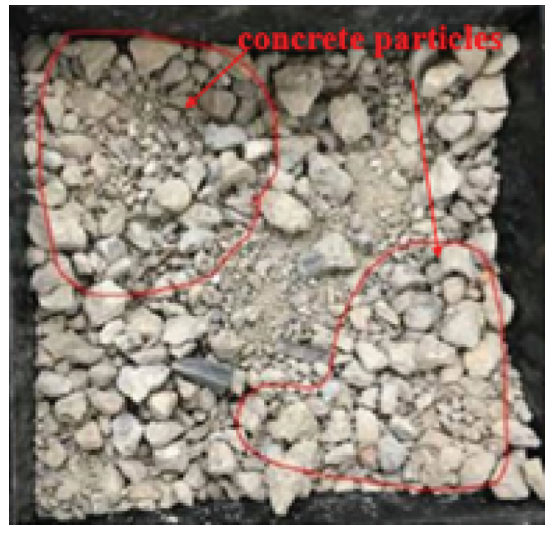

(a)

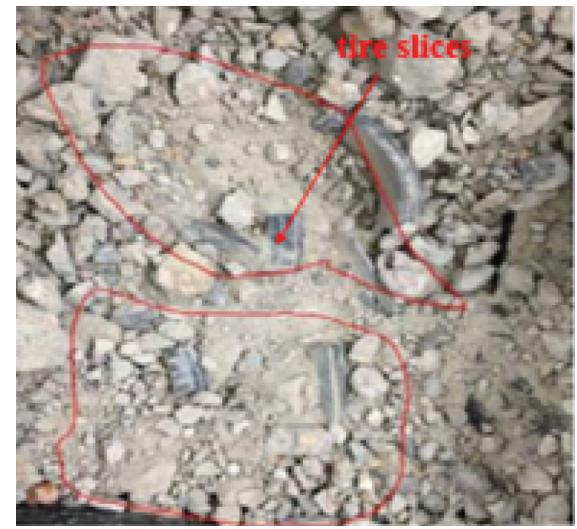

(b)

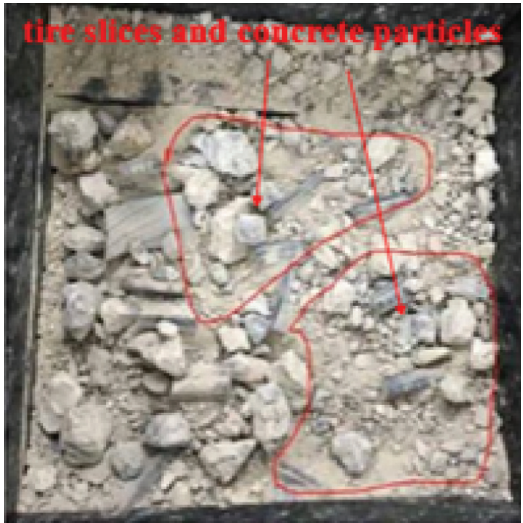

(c)

Figure 9: Contact state between concrete particles and tire slices.

the tire slices to the concrete particles were insufficient, and the shear strength of the concrete particles was increased.

3.6. Mechanism Analysis. Because the concrete particles are randomly shaped particles, as the vertical load increases, the concrete particles gradually generate relative displacement under the load. At the same time, particles are squeezed, broken, and embedded. When the particles move relative to each other, the interlocking effect may occur after the particles slide relative to each other. The interlocking effect not only increases the friction and cohesion between the particles in the sample but also fills the gap between the particles, making the internal gap of the soil smaller and smaller, and the bond between the concrete particles becomes closer and closer, finally reaching a limit. At this time, the shear stress is the peak shear strength. The working mechanism of concrete particles subjected to external loads is shown in Figure 8.

When the tire slices are added to the concrete particles, the natural curvature of the tire will exert a wrapping force on the concrete particles, the inner and outer lines of the tire 


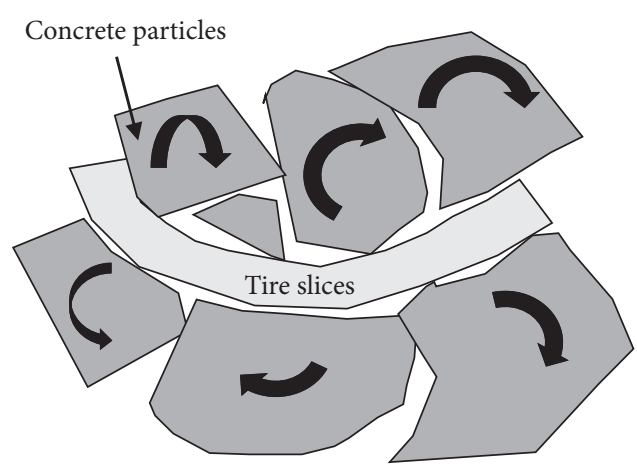

(a)

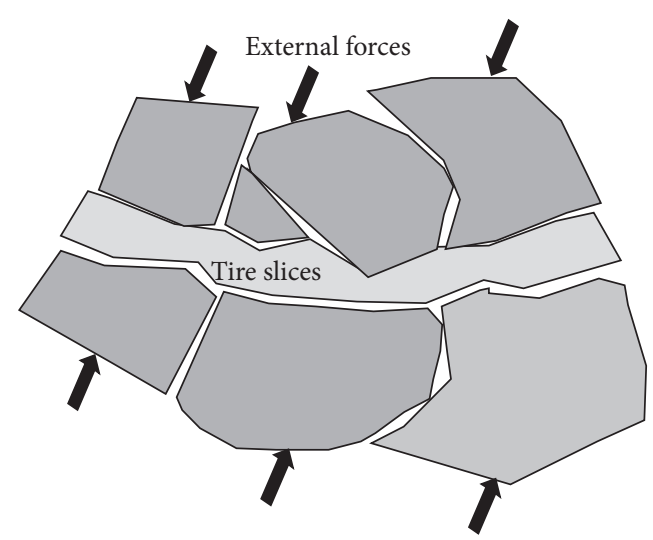

(b)

FIGURE 10: Changes of concrete particles reinforced with tire slices under external load.

will cause friction with the concrete, and the entanglement force and friction will strengthen the effect. As shown in Figure 9, the combination between the tire slices and the concrete particles is closer than that between the concrete particles.

As the concrete particles are irregular-shaped particles, the concrete particles will interact with the tire patch after bearing the external load. The stiffness of the concrete particles is far greater than that of the tire patch, and the tire patch will penetrate into the tire patch after bearing the force. A similar mechanism of action between brick powder particles and tire slices was confirmed by Ma et al. [15]. At this time, the tire will give a reaction force to the concrete particles and increase the cohesion and friction in the sample. The action mechanism of reinforced concrete particles with tire slices under external loads is shown in Figure 10.

From Figure 10, it can be seen that when the reinforced concrete particles are subjected to force, the bonding between the concrete particles and the tire slices will be closer and the stiffness of the tire slices is much lower than that of the concrete particles. The external force will make the surface of the tire slices change along the concave and convex surface of the concrete, fill the gap between the concrete particles, and make the internal bonding of the samples closer.

\section{Conclusions}

Based on the large-scale direct shear test in the laboratory, the shear mechanical properties of the reinforced concrete particles with tire slices were studied, the optimum tire volume content was determined, and the working mechanism of reinforced concrete particles with tire slices was analyzed. The main conclusions are as follows:

(1) The shear strength of concrete particles increases with the reinforcement of tire slices, and the peak shear stress increases with the increase of vertical load. The residual shear strength of the samples also increases, which enhances the deformation resistance of the samples. The peak growth rate of shear stress increases first and then decreases with the increase of vertical load.

(2) Vertical load can also affect the reinforcing effect of tire slices. Under $60 \mathrm{kPa}$ vertical load, the reinforcing effect of $4 \%$ tire volume content is the most significant, and the peak shear stress increases by $46.53 \%$.

(3) Compared with pure concrete particles, the internal friction angle and cohesion of samples increase greatly after adding tire flakes. The reinforcing effect of tire slice increases first and then decreases with the increase of the reinforcement ratio. When the tire volume content is $4 \%$, the reinforcing effect is the best. At this time, compared with the tire volume contents of $2 \%$ and $6 \%$, the internal friction angle and cohesion increase slightly.

(4) When the tire volume content is $4 \%$ under $60 \mathrm{kPa}$ vertical load, the shear rate has little effect on the peak shear strength. The faster the shear rate reaches the peak shear strength, the smaller the shear displacement is and the faster the shear strength decreases after the peak value is reached. The smaller the shear rate is, the more gently the shear strength decreases.

\section{Data Availability}

The data used to support the findings of this study are available from the corresponding author upon request.

\section{Conflicts of Interest}

The authors declare that there are no conflicts of interest regarding the publication of this article.

\section{Acknowledgments}

This work was supported by grants from National Natural Science Foundation of China (NSFC) (Grant no. 51678223) and Green Industrial Project of Hubei University of Technology (Grant nos. YXQN2017001 and BSQD12153). The 
authors would like to express their appreciation to these financial assistances.

\section{References}

[1] J. K. Kim and S. H. Lee, "New technology of crumb rubber compounding for recycling of waste tires," Journal of Applied Polymer Science, vol. 78, no. 8, pp. 1573-1577, 2000.

[2] S. Singh, W. Nimmo, M. T. Javed, and P. T. Williams, "Cocombustion of pulverized coal with waste plastic and tire rubber powders," Energy \& Fuels, vol. 25, no. 1, pp. 108-118, 2011.

[3] W. Yangzhuo, N. I. Mingfang, W. Zheng, and K. Luqian, "Study on recycling and utilization of waste tires for resource saving," Recyclable Resources and Circular Economy, vol. 1, pp. 34-36, 2012.

[4] C. E. Pierce and M. C. Blackwell, "Potential of scrap tire rubber as lightweight aggregate in flowable fill," Waste Management, vol. 23, no. 3, pp. 197-208, 2003.

[5] A. Yilmaz and N. Degirmenci, "Possibility of using waste tire rubber and fly ash with portland cement as construction materials," Waste Management, vol. 29, no. 5, pp. 1541-1546, 2009.

[6] W. Shen, L. Shan, T. Zhang, H. Ma, Z. Cai, and H. Shi, "Investigation on polymer-rubber aggregate modified porous concrete," Construction and Building Materials, vol. 38, pp. 667-674, 2013.

[7] A. Meddah and K. Merzoug, "Feasibility of using rubber waste fibers as reinforcements for sandy soils," Innovative Infrastructure Solutions, vol. 2, no. 1, p. 5, 2017.

[8] R. Siddique and T. R. Naik, "Properties of concrete containing scrap-tire rubber-an overview," Waste Management, vol. 24, no. 6, pp. 563-569, 2004.

[9] Y. W. Yoon, S. H. Cheon, and D. S. Kang, "Bearing capacity and settlement of tire-reinforced sands," Geotextiles and Geomembranes, vol. 22, no. 5, pp. 439-453, 2004.

[10] S. B. Reddy and A. M. Krishna, "Sand-tire chip mixtures for sustainable geoengineering applications," in Sustainability Issues in Civil Engineering, Springer, Singapore, 2017.

[11] M. Abbaspour, E. Aflaki, and F. Moghadas Nejad, "Reuse of waste tire textile fibers as soil reinforcement," Journal of Cleaner Production, vol. 207, pp. 1059-1071, 2019.

[12] M. Ghazavi and M. A. Sakhi, "Influence of optimized tire shreds on shear strength parameters of sand," International Journal of Geomechanics, vol. 5, no. 1, pp. 58-65, 2005.

[13] P. Anbazhagan, D. R. Manohar, and D. Rohit, "Influence of size of granulated rubber and tyre chips on the shear strength characteristics of sand-rubber mix," Geomechanics and Geoengineering, vol. 12, no. 4, pp. 1-13, 2016.

[14] S. M. Anvari, I. Shooshpasha, and S. S. Kutanaei, "Effect of granulated rubber on shear strength of fine-grained sand," Journal of Rock Mechanics and Geotechnical Engineering, vol. 9, no. 5, pp. 936-944, 2017.

[15] Q. Ma, Q. Deng, J. Mou, S. Yang, and X. Zhang, "Large-scale direct shear test on scrap tire strip reinforced brick powder," Advances in Civil Engineering, vol. 2019, Article ID 6046037, 11 pages, 2019.

[16] S. M. Anvari and I. Shooshpasha, "Influence of size of granulated rubber on bearing capacity of fine-grained sand," Arabian Journal of Geosciences, vol. 9, no. 18, p. 707, 2016.

[17] A. Nakhaei, S. M. Marandi, S. Sani Kermani, and M. H. Bagheripour, "Dynamic properties of granular soils mixed with granulated rubber," Soil Dynamics and Earthquake Engineering, vol. 43, no. 12, pp. 124-132, 2012.
[18] M. N. Sheikh, M. S. Mashiri, J. S. Vinod, and H.-H. Tsang, "Shear and compressibility behavior of sand-tire crumb mixtures," Journal of Materials in Civil Engineering, vol. 25, no. 10, pp. 1366-1374, 2013.

[19] M. S. Mashiri, J. S. Vinod, M. N. Sheikh, and H.-H. Tsang, "Shear strength and dilatancy behaviour of sand-tyre chip mixtures," Soils and Foundations, vol. 55, no. 3, pp. 517-528, 2015.

[20] R. Noorzad and M. Raveshi, "Mechanical behavior of waste tire crumbs-sand mixtures determined by triaxial tests," Geotechnical and Geological Engineering, vol. 35, no. 4, pp. 1793-1802, 2017.

[21] Y. Shenglan, "Analysis on the present situation and treatment of comprehensive utilization of construction waste in China," Journal of Green Science and Technology, vol. 18, pp. 128-131, 2018.

[22] Z. X. Chen, L. Wang, and L. Y. Wei, "Pavement performance study of construction waste and river sludge used as subgrade filling," Applied Mechanics and Materials, vol. 71-78, pp. 603-606, 2011.

[23] B. K. Liu, J. S. Fan, H. M. Hu, and L. H. Fu, "Recycled technology of urban road construction waste and miscellaneous fill used as subgrade fillings," Advanced Materials Research, vol. 250-253, pp. 3460-3464, 2011.

[24] L. Bai and C. X. Zhang, "The applied research for filling subgrade with construction waste," Advanced Materials Research, vol. 512-515, pp. 2995-2998, 2012.

[25] A. Rao, K. N. Jha, and S. Misra, "Use of aggregates from recycled construction and demolition waste in concrete," Resources, Conservation and Recycling, vol. 50, no. 1, pp. 7181, 2007.

[26] C. S. Vieira, P. M. Pereira, and M. D. L. Lopes, "Recycled construction and demolition wastes as filling material for geosynthetic reinforced structures. interface properties," Journal of Cleaner Production, vol. 124, pp. 299-311, 2016.

[27] W. C. Tang, H. Z. Cui, and Y. Lo, "Properties of concrete containing scrap-tire chips," Advanced Materials Research, vol. 399-401, pp. 1251-1256, 2011.

[28] D. J. U. Infante, G. M. A. Martinez, P. A. Arrua, and M. Eberhardt, "Shear strength behavior of different geosynthetic reinforced soil structure from direct shear test," International Journal of Geosynthetics and Ground Engineering, vol. 2, no. 2, 2016.

[29] C. S. Vieira and P. M. Pereira, "Interface shear properties of geosynthetics and construction and demolition waste from large-scale direct shear tests," Geosynthetics International, vol. 23, no. 1, pp. 62-70, 2016. 